\title{
ARTICLE
}

Clinical Study

\section{A multicentre, open-label, phase-I/randomised phase-II study to evaluate safety, pharmacokinetics, and efficacy of nintedanib vs. sorafenib in European patients with advanced hepatocellular carcinoma}

\author{
D. H. Palmer ${ }^{1,2}$, Y. T. Ma $^{3}$, M. Peck-Radosavljevic ${ }^{4}$, P. Ross ${ }^{5}$, J. Graham $^{6}$, L. Fartoux ${ }^{7}$, A. Deptala ${ }^{8}$, M. Studeny ${ }^{9}$, D. Schnell ${ }^{9}$, J. Hocke $^{9}$,
} A-B. Loembé ${ }^{10}$ and T. Meyer ${ }^{11}$

BACKGROUND: This multicentre, open-label, phase-l/randomised phase-II trial evaluated safety, pharmacokinetics, maximumtolerated-dose (MTD) per dose-limiting toxicities (DLTs), and efficacy of nintedanib vs. sorafenib in European patients with unresectable advanced hepatocellular carcinoma (aHCC).

METHODS: Phase I: Patients were stratified into two groups per baseline aminotransferase/alanine aminotransferase and ChildPugh score; MTD was determined. Phase II: Patients were randomised 2:1 to nintedanib (MTD) or sorafenib (400-mg bid) in 28-day cycles until intolerance or disease progression. Time-to-progression (TTP, primary endpoint), overall survival (OS) and progressionfree survival (PFS) were determined.

RESULTS: Phase-I: no DLTs observed; nintedanib MTD in both groups was $200 \mathrm{mg}$ bid. Phase-II: patients

$(N=93)$ were randomised to nintedanib $(n=62)$ or sorafenib $(n=31)$; TTP was 5.5 vs. 4.6 months $(\mathrm{HR}=1.44[95 \% \mathrm{Cl}, 0.81-2.57])$, OS was 11.9 vs. 11.4 months ( $\mathrm{HR}=0.88$ [95\% Cl, 0.52-1.47]), PFS was 5.3 vs. 3.9 months $(\mathrm{HR}=1.35$ [95\% Cl, 0.78-2.34]),

respectively (all medians). Dose intensity and tolerability favoured nintedanib. Fewer patients on nintedanib (87.1\%) vs. sorafenib (96.8\%) had drug-related adverse events (AEs) or grade $\geq 3$ AEs (67.7\% vs. 90.3\%), but more patients on nintedanib (28 [45.2\%]) had AEs leading to drug discontinuation than did those on sorafenib (7 [22.6\%]).

CONCLUSIONS: Nintedanib may have similar efficacy to sorafenib in aHCC.

British Journal of Cancer (2018) 118:1162-1168; https://doi.org/10.1038/s41416-018-0051-8

\section{INTRODUCTION}

Hepatocellular carcinoma (HCC) is a hyper-vascular tumour ${ }^{1}$ involving dysregulation of several angiogenic growth factors such as vascular endothelial growth factor (VEGF), ${ }^{2-4}$ epidermal growth factor (EGF), ${ }^{2-4}$ platelet-derived growth factor (PDGF) ${ }^{2-4}$ and fibroblast growth factor (FGF) ${ }^{5}$ Sorafenib is a small-molecule kinase inhibitor of VEGFR, PDGFR, RAF, c-KIT and FLT- ${ }^{6}$, and is the first approved targeted drug worldwide for first-line treatment in advanced HCC. Phase III trials in Western ${ }^{7}$ and Asian patients ${ }^{6}$ have shown it to significantly improve overall survival (OS) compared with placebo. However, the effect of sorafenib in HCC is modest, with median survival prolonged by 2-3 months compared with placebo. ${ }^{6,7}$

Primary resistance to VEGF-targeted therapy, such as sorafenib, may occur through a variety of mechanisms, ${ }^{8,9}$ which may be overcome by targeting multiple pathways either through combination regimens or drugs with multiple targets? Nintedanib is an oral, small-molecule, triple angiokinase inhibitor of VEGFR1-3, PDGFRa and $\beta$, FGFR1-3, Flt-3, Lck, Lyn and $\mathrm{Src}^{10}$ with anti-tumour and anti-angiogenic activity in preclinical models of HCC.$^{11}$ Nintedanib is metabolised in the liver ${ }^{12}$, and it is not clear if liver impairment influences nintedanib's metabolism, elimination, tolerability and maximumtolerated dose (MTD). Because of this, the published guidelines for HCC drug development recommend initial phase-I trials to determine the MTD of a novel agent in the context of chronic liver disease followed by randomised phase-Il trials with time to progression (TTP) as the primary endpoint.$^{13}$ Nintedanib for HCC has been developed in accordance with these guidelines. We report the results of a multicentre,

\footnotetext{
${ }^{1}$ Department of Molecular and Clinical Cancer Medicine, University of Liverpool, Liverpool, United Kingdom; ${ }^{2}$ Clatterbridge Cancer Centre, Bebington, United Kingdom; ${ }^{3}$ School of

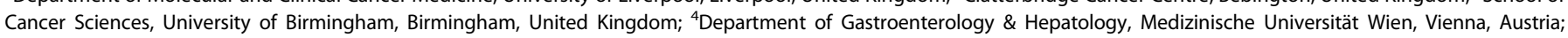

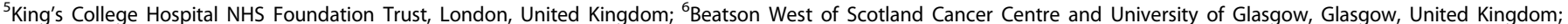

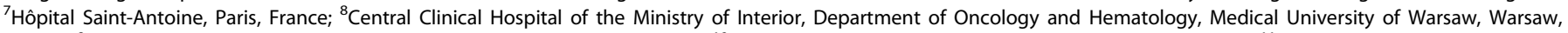

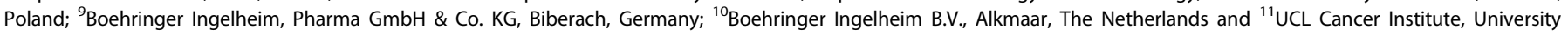
College London, London, United Kingdom

Correspondence: D H. Palmer (Daniel.Palmer@liverpool.ac.uk)
}

Received: 27 July 2017 Revised: 31 January 2018 Accepted: 12 February 2018

Published online: 22 March 2018 
open-label, randomised phase-I/II trial that evaluated the MTD, pharmacokinetics (PK), efficacy and safety of nintedanib vs. sorafenib in European patients with advanced HCC, who did not have prior systemic treatment (NCT01004003; 1199.37). Since different risk factors between Western and Asian populations, such as incidences of hepatitis B virus (HBV) and hepatitis $C$ virus (HCV), may influence responses to targeted therapies, an identically designed study was conducted in parallel in Asian patients ${ }^{14,15}$ and is reported separately (NCT00987935; 1199.39)

\section{MATERIALS AND METHODS}

Study population and eligibility

Key inclusion criteria included patients aged $\geq 18$ years with advanced HCC not amenable to curative/locoregional therapy and with $\geq 1$ measurable lesion by Response Evaluation Criteria in Solid Tumours (RECIST) v1.0 (for phase-II); Eastern Cooperative Oncology Group (ECOG) performance score (PS) $\leq 2$; Child-Pugh score 5-6 (for phase-II) and alanine/aspartate aminotransferase (ALT/AST) levels $\leq 2$ times upper limit of normal (ULN) (for phase-II and phase-I group I; phase-I group II had ALT or AST $>2-\leq 5$ times ULN or Child-Pugh score 7); $>4$ weeks since most recent local therapy; no prior systemic therapy for HCC; no history of other malignancy within the past 3 years; and life expectancy $\geq 12$ weeks. Additional inclusion criteria are listed in the protocol. The trial protocol was reviewed by the institutional review board of each participating centre and conforms to the Helsinki Declaration. All patients provided written informed consent (ClinicalTrials.gov registration: NCT01004003).

\section{Study design and treatment}

The primary endpoint for phase-I was nintedanib MTD determination in terms of dose-limiting toxicities (DLTs) occurring during the MTD determination period (i.e. within the first 28 days of therapy). Pharmacokinetics of nintedanib and its main metabolites BIBF 1202 and BIBF 1202 glucuronide were assessed as an exploratory endpoint. In view of the observed DLT of transaminitis in the nonHCC oncology population, patients were stratified into two groups according to their ALT/AST and Child-Pugh score at baseline. Group I contained patients with ALT and AST $\leq 2$ times ULN and Child-Pugh score 5-6, while group II contained patients with ALT or AST $>2-\leq 5$ times ULN or Child-Pugh score 7. An expansion cohort of group II patients was started. MTD determination methods and DLT definitions for nintedanib appear in supplementary Data.

Extensive plasma and urine sampling was performed during the first treatment cycle to describe the PK characteristics of nintedanib and its main metabolites BIBF 1202 and BIBF 1202 glucuronide. Assessments were performed according to the schedule shown in the protocol. Antiviral treatment was recommended for patients with chronic HBV infection.

For phase-II, 93 patients were randomised in a 2:1 ratio to receive nintedanib $200 \mathrm{mg}$ bid $(n=62)$ or sorafenib $400 \mathrm{mg}$ bid ( $n$ =31) continuously, in 28-day cycles, until intolerable AEs or disease progression (PD). A randomised design was used in favour of performing an uncontrolled trial, which was common at the time the trial was conceived, to permit a contemporaneous comparison against sorafenib. A 2:1 randomisation ratio was chosen to generate more data on nintedanib, especially regarding safety, because data for sorafenib were already extensively defined. Treatment beyond PD was allowed at the discretion of the investigator if there was perceived ongoing clinical benefit.

Randomisation was performed by an integrated response system using a validated randomisation number-generating system. Randomisation was stratified by presence of extrahepatic spread (EHS) and macrovascular invasion (MVI) (EHS and/or MVI present vs. both absent). Full details of randomisation, as well as the dose reduction scheme and trial procedures and assessments, are shown in the protocol and supplementary Data.

\section{Study outcomes}

The primary endpoints for phase-I and II, respectively, were determination of the MTD in terms of DLTs and TTP by central independent review (CIR) according to RECIST v1.0 (which were the recommended criteria when the protocol was written). Main secondary endpoints for phase-II were objective tumour response (OR) according to RECIST V1.0 assessed by CIR, defined as a best response of complete response (CR) or partial response (PR); progression-free survival (PFS) assessed by $\mathrm{CIR}$; and OS. Definitions and further outcome measures are described in supplementary Data.

The primary analysis for efficacy and safety was performed after $80 \%$ of all planned patients ( $77 \%$ of all included patients) had an investigator-assessed TTP event.

Safety and tolerability were assessed based on the incidence and severity of adverse events (AEs) according to CTCAE v3.0, laboratory abnormalities, physical examination, ECOG PS, vital signs and electrocardiogram.

Pharmacokinetic sampling

See supplementary Data for details.

Statistical analysis

All analyses were exploratory; any statistical tests were performed only to provide a statistical framework from which to view the results and aid planning of further studies. The sample size was selected to provide a high probability of recording a numerically positive treatment effect of nintedanib vs. sorafenib. By assuming median TTPs of 9 months for nintedanib and 6 months for sorafenib (hazard ratio [HR] 0.67) to represent a clinically significant benefit compared with sorafenib, the probability of observing any numerically positive treatment effect on TTP (i.e. an estimated HR for TTP between nintedanib and sorafenib of $<1$ ) is around $93 \%$ for 90 patients (2:1 randomisation, 8 months accrual and 14 months follow-up). See supplementary Data for further details.

WinNonlin 5.2 (Certara, Princeton, NJ, USA) and SAS Version 9.2 (SAS, Cary, NC, USA) were used for all statistical and PK analyses.

\section{RESULTS}

Patient characteristics

Between November 11, 2009 and September 24, 2013, a total of 32 patients (13 in group I and 19 in group II) were recruited in phase-I from 4 centres in 2 European countries. Six patients were screened, but did not enter the trial. Supplementary Table S1 summarises patient demographics and baseline disease characteristics; supplementary Table S2 shows the patient disposition.

For phase-II, of the 132 enroled patients, 93 were randomly assigned from September 19, 2011 until November 14, 2012, with all receiving at least one dose of nintedanib $(n=62)$ or sorafenib $(n=31$; supplementary Figure S1). There were 28 investigational sites in eight European countries involved in enrolment, of which 26 randomised and treated patients. With the exception of no evidence of parenchymal liver disease $(24.2 \%$ in the nintedanib group vs. $3.2 \%$ in the sorafenib group), and HBV-related liver disease $(6.5 \%$ in the nintedanib group vs. $22.6 \%$ in the sorafenib group), baseline characteristics were well-balanced between the two treatment groups. Approximately three quarters of all patients in both groups were Barcelona Clinic Liver Cancer (BCLC) stage $C$ (and the remainder mostly stage $B$ ). Table 1 summarises baseline patient characteristics. 
Table 1. Phase-Il patient baseline demographics and clinical characteristics $^{\text {a }}$

\begin{tabular}{|c|c|c|c|}
\hline Characteristic & $\begin{array}{l}\text { Nintedanib, } 200 \\
\mathrm{mg} \text { bid }(n=62)\end{array}$ & $\begin{array}{l}\text { Sorafenib, } 400 \\
\mathrm{mg} \text { bid }(n=31)\end{array}$ & $\begin{array}{l}\text { Total }(N= \\
93)\end{array}$ \\
\hline $\begin{array}{l}\text { Median age, years } \\
\text { (range) }\end{array}$ & 66 (34-86) & $64(28-83)$ & $66(28-86)$ \\
\hline Male sex, $n(\%)$ & $48(77.4)$ & $26(83.9)$ & 74 (79.6) \\
\hline \multicolumn{4}{|l|}{ Race, $n(\%)$} \\
\hline Indian & $0(0.0)$ & $3(9.7)$ & $3(3.2)$ \\
\hline $\begin{array}{l}\text { Taiwanese or } \\
\text { Chinese }\end{array}$ & $0(0.0)$ & $1(3.2)$ & $1(1.1)$ \\
\hline Black & $0(0.0)$ & $1(3.2)$ & $1(1.1)$ \\
\hline Caucasian & 57 (91.9) & $24(77.4)$ & $81(87.1)$ \\
\hline Missing & $5(8.1)$ & $2(6.5)$ & $7(7.5)$ \\
\hline $\begin{array}{l}\text { Median time since } \\
\text { diagnosis, months } \\
\text { (range) }\end{array}$ & $2.53(0-101.4)$ & $2.76(0.2-77.5)$ & $\begin{array}{l}2.53 \\
(0-101.4)\end{array}$ \\
\hline \multicolumn{4}{|l|}{ ECOG PS, $n(\%)$} \\
\hline 0 & $32(51.6)$ & $18(58.1)$ & $50(53.8)$ \\
\hline 1 & $28(45.2)$ & $10(32.3)$ & $38(40.9)$ \\
\hline 2 & $2(3.2)$ & $3(9.7)$ & $5(5.4)$ \\
\hline \multicolumn{4}{|c|}{ Child-Pugh score, $n$ (\%) } \\
\hline 5 & $42(67.7)$ & $23(74.2)$ & $65(69.9)$ \\
\hline 6 & $19(30.6)$ & $8(25.8)$ & $27(29.0)$ \\
\hline $7^{b}$ & $1(1.6)$ & $0(0.0)$ & $1(1.1)$ \\
\hline \multicolumn{4}{|l|}{ BCLC stage, $n(\%)$} \\
\hline 0 & $0(0.0)$ & $1(3.2)$ & $1(1.1)$ \\
\hline A & $1(1.6)$ & $0(0.0)$ & $1(1.1)$ \\
\hline B & $15(24.2)$ & $7(22.6)$ & $22(23.7)$ \\
\hline$C$ & 45 (72.6) & $23(74.2)$ & $68(73.1)$ \\
\hline$D$ & $1(1.6)$ & $0(0.0)$ & $1(1.1)$ \\
\hline MVI, $n(\%)$ & $22(35.5)$ & $9(29.0)$ & $31(33.3)$ \\
\hline EHS, $n(\%)$ & $40(64.5)$ & $21(67.7)$ & $61(65.6)$ \\
\hline \multicolumn{4}{|l|}{ Location of EHS, $n$ (\%) } \\
\hline Bone & $6(9.7)$ & $5(16.1)$ & $11(11.8)$ \\
\hline Lung & $16(25.8)$ & $6(19.4)$ & $22(23.7)$ \\
\hline Lymph & $26(41.9)$ & $9(29.0)$ & 35 (37.6) \\
\hline Other & $11(17.7)$ & 7 (22.6) & $18(19.4)$ \\
\hline \multicolumn{4}{|c|}{ Aetiology of parenchymal liver disease, $n(\%)$} \\
\hline Alcohol related & $10(16.1)$ & $3(9.7)$ & $13(14.0)$ \\
\hline $\mathrm{HBV}$ related & $4(6.5)$ & $7(22.6)$ & $11(11.8)$ \\
\hline $\mathrm{HCV}$ related & $13(21.0)$ & $8(25.8)$ & $21(22.6)$ \\
\hline $\begin{array}{l}\mathrm{HBV}+\mathrm{HCV} \\
\text { related }\end{array}$ & $0(0.0)$ & $0(0.0)$ & $0(0.0)$ \\
\hline Unknown & $23(37.1)$ & $8(25.8)$ & $31(33.3)$ \\
\hline Other & $12(19.4)$ & $5(16.1)$ & $17(18.3)$ \\
\hline \multicolumn{4}{|c|}{ Parenchymal liver disease, n (\%) } \\
\hline Chronic hepatitis & $8(12.9)$ & $5(16.1)$ & $13(14.0)$ \\
\hline Steatofibrosis & $3(4.8)$ & $2(6.5)$ & $5(5.4)$ \\
\hline Cirrhosis & $29(46.8)$ & $20(64.5)$ & $49(52.7)$ \\
\hline No evidence & $15(24.2)$ & $1(3.2)$ & $16(17.2)$ \\
\hline Unknown & $6(9.7)$ & $3(9.7)$ & $9(9.7)$ \\
\hline Other & $1(1.6)$ & $0(0.0)$ & $1(1.1)$ \\
\hline \multicolumn{4}{|c|}{ Type of local therapy, $n(\%)$} \\
\hline $\begin{array}{l}\text { Complete surgical } \\
\text { resection }\end{array}$ & $9(14.5)$ & $3(9.7)$ & $12(12.9)$ \\
\hline RFA & $2(3.2)$ & $0(0.0)$ & $2(2.2)$ \\
\hline
\end{tabular}

\begin{tabular}{|c|c|c|c|}
\hline \multicolumn{4}{|l|}{ Table 1 continued } \\
\hline Characteristic & $\begin{array}{l}\text { Nintedanib, } 200 \\
\mathrm{mg} \text { bid }(n=62)\end{array}$ & $\begin{array}{l}\text { Sorafenib, } 400 \\
\mathrm{mg} \text { bid }(n=31)\end{array}$ & $\begin{array}{l}\text { Total }(N= \\
93)\end{array}$ \\
\hline PEI & $0(0.0)$ & $0(0.0)$ & $0(0.0)$ \\
\hline TACE & $19(30.6)$ & $10(32.3)$ & $29(31.2)$ \\
\hline RT & $1(1.6)$ & $0(0.0)$ & $1(1.1)$ \\
\hline Other & $2(3.2)$ & $4(12.9)$ & $6(6.5)$ \\
\hline \multicolumn{4}{|c|}{ Stratification group, n (\%) } \\
\hline $\begin{array}{l}\text { I: EHS and/or MVI } \\
\text { present }\end{array}$ & $49(79.0)$ & $23(74.2)$ & $72(77.4)$ \\
\hline $\begin{array}{l}\text { II: EHS and MVI } \\
\text { both absent }\end{array}$ & $13(21.0)$ & $8(25.8)$ & $21(22.6)$ \\
\hline \multicolumn{4}{|c|}{$\begin{array}{l}\text { BCLC Barcelona Clinic Liver Cancer, ECOG PS Eastern Cooperative Oncology } \\
\text { Group performance status, EHS extrahepatic spread, HBV hepatitis B, HCV } \\
\text { hepatitis C, MVI macrovascular invasion, PEI percutaneous ethanol } \\
\text { injection, RFA radiofrequency ablation, RT radiotherapy, TACE transarterial } \\
\text { chemoembolisation. a } \alpha \text {-fetoprotein (AFP) groups are not shown because } \\
\text { there were too many missing values because a lot of investigative sites } \\
\text { measured activated AFP instead of AFP and there is no transformation of } \\
\text { the values available. }{ }^{b} \text { This patient with a Child-Pugh score of } 7 \text { in the } \\
\text { nintedanib group was a protocol deviation }\end{array}$} \\
\hline
\end{tabular}

Patient disposition and treatment exposure

The median (range) duration of treatment in phase-I was $11.3(0.07-40.5)$ months in group I vs. 2.14 (0.03-14.1) months in group II. Median dose intensity for all dose cohorts was $100 \%$, with the exception of the $200 \mathrm{mg}$ cohort in group I, which was 99.3\%. Nintedanib dose reductions and exposure for phase-I are summarised in supplementary Table S3.

In phase-II, the median durations of nintedanib and sorafenib treatments were similar (5.40 months and 5.42 months, respectively). However, the mean treatment duration was nominally longer in the nintedanib (8.08 months) vs. the sorafenib (7.28 months) group. Mean dose intensity was also higher for nintedanib $(96.4 \%$ in the nintedanib vs. $84.8 \%$ in the sorafenib group).

\section{Determination of MTD}

There were no DLTs during the MTD determination period in either group at any dose up to the prespecified maximum of 200 $\mathrm{mg}$ bid. Thus, the recommended phase-ll dose was determined to be $200 \mathrm{mg}$ bid for group I and II patients. DLTs experienced after the MTD determination period are described in supplementary Data.

Pharmacokinetics

PK results appear in supplementary Data. In brief, nintedanib was rapidly absorbed followed by at least biphasic disposition kinetics (supplementary Figure S2). Maximum plasma concentrations were achieved around a median of $2 \mathrm{~h}$ and the gMean half-life ranged between 18.3 and $33.0 \mathrm{~h}$ (supplementary Table S4). We observed a trend towards an increased gMean exposure to nintedanib, BIBF 1202 and BIBF 1202 glucuronide in group II patients compared with those of group I (supplementary Table S5). However, the range of individual values strongly overlapped when data from both groups were compared.

Phase-Il efficacy

Primary endpoint. The median TTP according to RECIST $\mathrm{v} 1.0$ by $\mathrm{CIR}$ was 5.5 months $(95 \% \mathrm{Cl}, 3.0-5.6)$ in the nintedanib group vs. 4.6 months $(95 \% \mathrm{Cl}, 2.8-7.4)$ in the sorafenib group; $\mathrm{HR}=1.44$ (95\% Cl, 0.81-2.57) (Fig. 1a). 
A

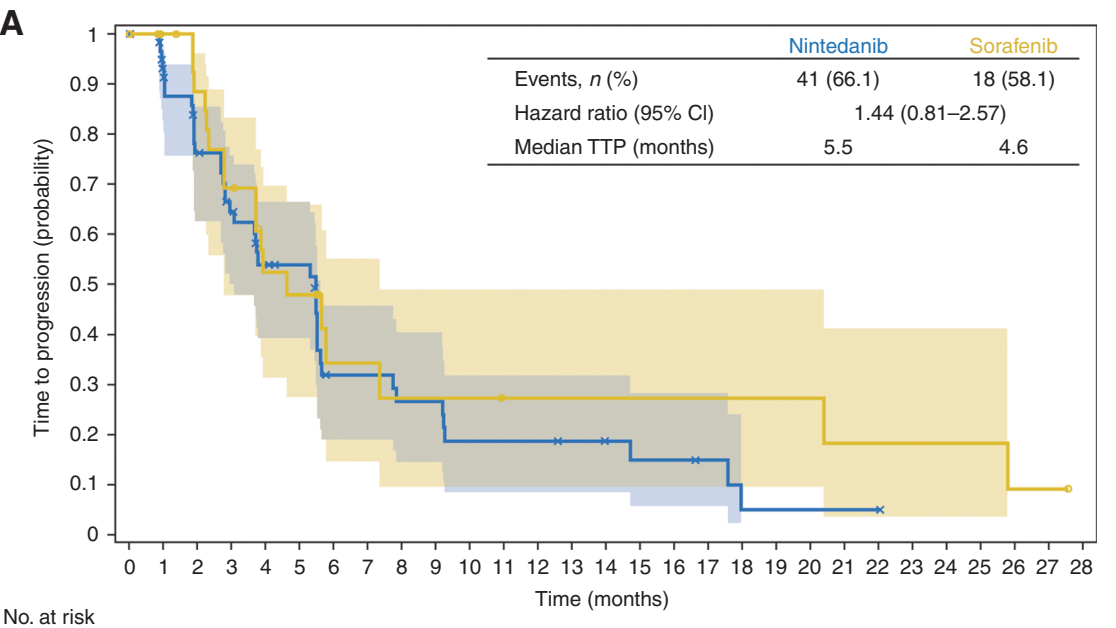

Nintedanib $6252 \quad 40 \begin{array}{lllllllllllllllllllll}25 & 25 & 23 & 12 & 12 & 10 & 10 & 7 & 7 & 7 & 6 & 5 & 4 & 4 & 3 & 1 & 1 & 1 & 1 & 1 & 0\end{array}$

$\begin{array}{llllllllllllllllllllllllllllll}\text { Sorafenib } & 31 & 27 & 23 & 18 & 12 & 11 & 5 & 5 & 4 & 4 & 4 & 3 & 3 & 3 & 3 & 3 & 3 & 3 & 3 & 3 & 3 & 2 & 2 & 2 & 2 & 2 & 1 & 1 & 0\end{array}$

\section{B}

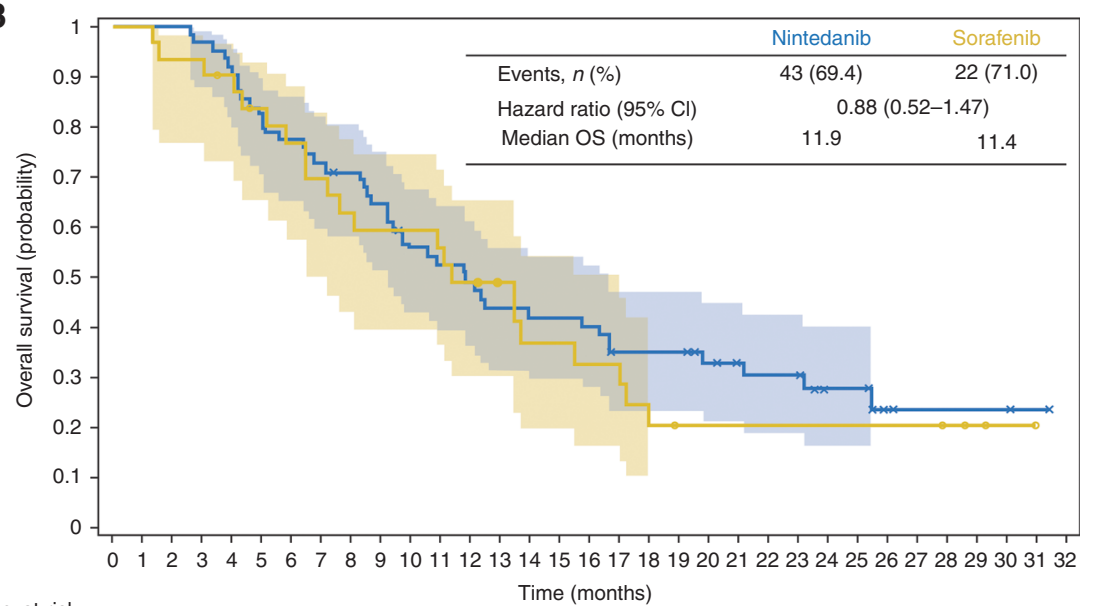

No. at risk

Nintedanib 62626260575148454339323028252424231919191513121288844222222110

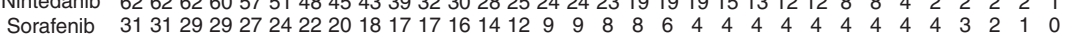

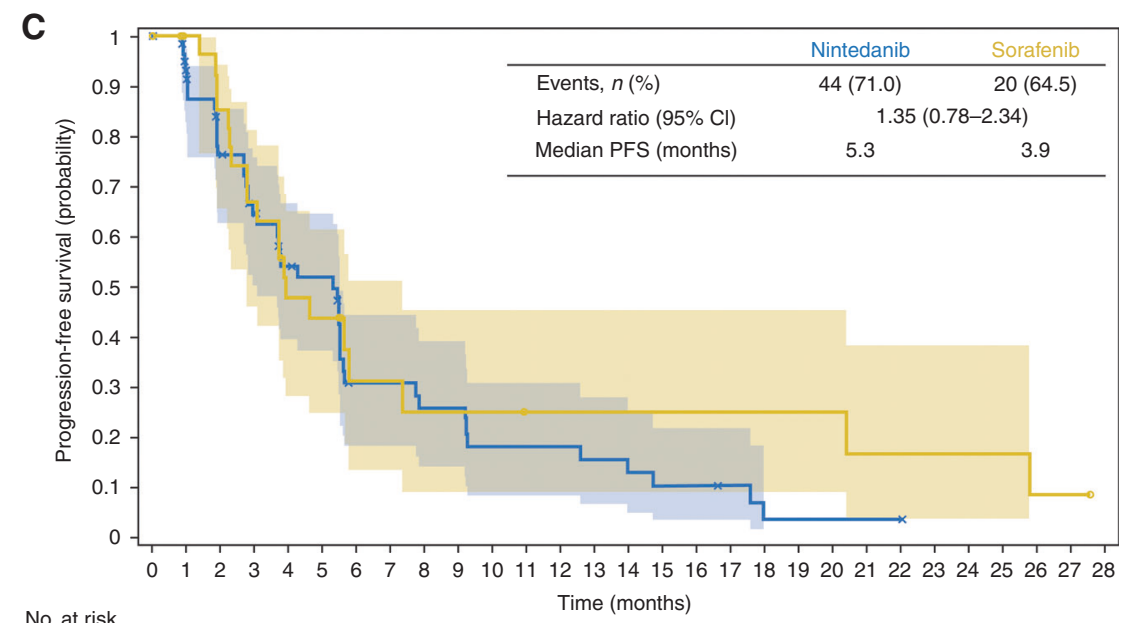

No. at risk

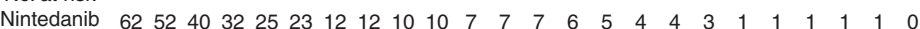

$\begin{array}{llllllllllllllllllllllllllllll}\text { Sorafenib } & 31 & 27 & 23 & 18 & 12 & 11 & 5 & 5 & 4 & 4 & 4 & 3 & 3 & 3 & 3 & 3 & 3 & 3 & 3 & 3 & 3 & 2 & 2 & 2 & 2 & 2 & 1 & 1 & 0\end{array}$

Fig. 1 Phase-II Kaplan-Meier curves of (A) time to tumour progression by central independent review assessed according to Response Evaluation Criteria for Solid Tumours (RECIST) v1.0, (B) overall survival, and (C) progression-free survival by central independent review assessed according to RECIST v1.0. OS, overall survival; PFS, progression-free survival; TTP, time to progression 
Table 2. Most frequently reported (patient level) adverse events by primary system organ class and preferred term (occurring at any grade in $\geq 20 \%$ or at grade $\geq 3$ in $\geq 5 \%$ patients in either treatment group) during the phase-Il portion

\begin{tabular}{|c|c|c|c|c|}
\hline \multirow[t]{2}{*}{$\begin{array}{l}\text { Adverse event } \\
\text { (SOC and PT) }\end{array}$} & \multicolumn{2}{|c|}{$\begin{array}{l}\text { Nintedanib, } 200 \mathrm{mg} \\
\text { bid } \\
(n=62)\end{array}$} & \multicolumn{2}{|c|}{$\begin{array}{l}\text { Sorafenib, } 400 \mathrm{mg} \\
\text { bid }(n=31)\end{array}$} \\
\hline & $\begin{array}{l}\text { All } \\
\text { grades, } \\
n(\%)\end{array}$ & $\begin{array}{l}\text { Grade } \geq 3, \\
n(\%)\end{array}$ & $\begin{array}{l}\text { All } \\
\text { grades, } \\
n(\%)\end{array}$ & $\begin{array}{l}\text { Grade } \\
\geq 3, n(\%)\end{array}$ \\
\hline $\begin{array}{l}\text { Patients with any adverse } \\
\text { event }\end{array}$ & $62(100)$ & $42(67.7)$ & $31(100)$ & $28(90.3)$ \\
\hline $\begin{array}{l}\text { Blood and lymphatic system } \\
\text { disorders }\end{array}$ & $10(16.1)$ & $5(8.1)$ & $8(25.8)$ & $6(19.4)$ \\
\hline Anaemia & $6(9.7)$ & $4(6.5)$ & $1(3.2)$ & $1(3.2)$ \\
\hline Thrombocytopenia & $2(3.2)$ & $1(1.6)$ & $4(12.9)$ & $3(9.7)$ \\
\hline Gastrointestinal disorders & $60(96.8)$ & $16(25.8)$ & $29(93.5)$ & $3(9.7)$ \\
\hline Diarrhoea & $44(71.0)$ & $8(12.9)$ & $21(67.7)$ & $1(3.2)$ \\
\hline Nausea & $30(48.4)$ & $1(1.6)$ & $9(29.0)$ & $0(0.0)$ \\
\hline Vomiting & $24(38.7)$ & $2(3.2)$ & $9(29.0)$ & $0(0.0)$ \\
\hline Abdominal pain & $16(25.8)$ & $0(0.0)$ & $9(29.0)$ & $1(3.2)$ \\
\hline Abdominal pain upper & $16(25.8)$ & $0(0.0)$ & $4(12.9)$ & $0(0.0)$ \\
\hline $\begin{array}{l}\text { General disorders and } \\
\text { administration site } \\
\text { conditions }\end{array}$ & $44(71.0)$ & $11(17.7)$ & $21(67.7)$ & $4(12.9)$ \\
\hline Fatigue & $35(56.5)$ & $7(11.3)$ & $10(32.3)$ & $1(3.2)$ \\
\hline Investigations & $24(38.7)$ & $14(22.6)$ & $17(54.8)$ & $11(35.5)$ \\
\hline AST increased & $11(17.7)$ & $7(11.3)$ & $5(16.1)$ & $1(3.2)$ \\
\hline ALT increased & $8(12.9)$ & $5(8.1)$ & $3(9.7)$ & $2(6.5)$ \\
\hline $\begin{array}{l}\text { Metabolism and nutrition } \\
\text { disorders }\end{array}$ & $26(41.9)$ & $4(6.5)$ & $18(58.1)$ & $4(12.9)$ \\
\hline Decreased appetite & $23(37.1)$ & $1(1.6)$ & $13(41.9)$ & $1(3.2)$ \\
\hline $\begin{array}{l}\text { Neoplasms benign, } \\
\text { malignant and unspecified } \\
\text { (including cysts and polyps) }\end{array}$ & $6(9.7)$ & $4(6.5)$ & $4(12.9)$ & $3(9.7)$ \\
\hline $\begin{array}{l}\text { Malignant neoplasm } \\
\text { progression }\end{array}$ & $2(3.2)$ & $2(3.2)$ & $3(9.7)$ & $3(9.7)$ \\
\hline Nervous system disorders & $20(32.3)$ & $7(11.3)$ & $16(51.6)$ & $2(6.5)$ \\
\hline Hepatic encephalopathy & $5(8.1)$ & $5(8.1)$ & $2(6.5)$ & $1(3.2)$ \\
\hline Lethargy & $5(8.1)$ & $0(0.0)$ & $8(25.8)$ & $1(3.2)$ \\
\hline $\begin{array}{l}\text { Skin and subcutaneous } \\
\text { tissue disorders }\end{array}$ & $27(43.5)$ & $2(3.2)$ & $25(80.6)$ & $11(35.5)$ \\
\hline Rash & $6(9.7)$ & $0(0.0)$ & $7(22.6)$ & $1(3.2)$ \\
\hline Alopecia & $3(4.8)$ & $0(0.0)$ & $11(35.5)$ & $0(0.0)$ \\
\hline $\begin{array}{l}\text { Palmar-plantar } \\
\text { erythrodysesthesia } \\
\text { syndrome }\end{array}$ & $1(1.6)$ & $0(0.0)$ & $11(35.5)$ & $7(22.6)$ \\
\hline Skin reaction & $1(1.6)$ & $1(1.6)$ & $3(9.7)$ & $2(6.5$ \\
\hline
\end{tabular}

ALT alanine aminotransferase, $A S T$ aspartate aminotransferase, $P T$ preferred term, SOC system organ class

Secondary endpoints. Median OS was 11.9 months $(95 \% \mathrm{Cl}$, $9.2-16.7)$ in the nintedanib group vs. 11.4 months $(95 \% \mathrm{Cl}$, $6.5-17.0)$ in the sorafenib group; $\mathrm{HR}=0.88(95 \% \mathrm{Cl}, 0.52-1.47$; Fig. 1b).

Median PFS according to RECIST v1.0 by CIR was 5.3 months for nintedanib $(95 \% \mathrm{Cl}, 3.0-5.5)$ vs. 3.9 months for sorafenib $(95 \% \mathrm{Cl}$, 2.8-7.4); $\mathrm{HR}=1.35 \quad(95 \% \mathrm{Cl}, 0.78-2.34 ;$ Fig. 1c). Radiological response according to RECIST and mRECIST by CIR is summarised in supplementary Table S6, including the secondary endpoint OR according to RECIST by CIR. The best percentage change from baseline in target lesions by $\mathrm{CIR}$ for nintedanib and sorafenib are shown in supplementary Figure S3A and Figure S3B, respectively. One patient on nintedanib had a PR of 16.0 months duration according to RECIST by CIR; two patients on sorafenib had a PR that lasted for 1.9 months and 2.9 months. According to mRECIST by $\mathrm{CIR}$, there were seven patients on nintedanib and six patients on sorafenib with a PR. At the cut-off date of July 15, 2014, two patients on nintedanib and one on sorafenib continued treatment, with one patient on nintedanib continuing despite progression by RECIST. This patient continued on treatment beyond progression for 169 days.

One patient underwent resection following treatment on nintedanib and remains in complete remission; this was a noncirrhotic man who presented with a poorly vascularised HCC that did not respond to transarterial chemoembolisation. He was then offered systemic therapy and consented to participate in this study. Following a long period of disease control and multidisciplinary team review, he underwent surgical resection.

Exploratory endpoints. Median TTP as assessed by mRECIST by $\mathrm{CIR}$ in the nintedanib group was 5.5 months $(95 \% \mathrm{Cl}, 3.1-5.6)$ vs. 5.5 months in the sorafenib group $(95 \% \mathrm{Cl}, 2.8-7.4) ; \mathrm{HR}=1.59$ $(95 \% \mathrm{Cl}, 0.88-2.85)$ and median TTP by investigator assessment in the nintedanib group was 5.5 months $(95 \% \mathrm{Cl}, 3.1-7.4)$ vs. 3.8 months in the sorafenib group $(95 \% \mathrm{Cl}, 3.5$ to 5.7$)$; $\mathrm{HR}=1.05$ (95\% Cl, 0.63-1.76).

Median time to treatment failure was 3.7 months for nintedanib $(95 \% \mathrm{Cl}, 2.7-5.5)$ vs. 3.7 months for sorafenib (95\% Cl, 2.3-5.7); HR $=1.27(95 \% \mathrm{Cl}, 0.79-2.02)$. Subgroup analysis according to performance status, aetiology of parenchymal liver disease, baseline hypertension and EHS or MVI suggest no differences in TTP between the treatment arms, but subgroups were small (data not shown).

Safety and tolerability

AEs occurring during the phase-I portion are reported in supplementary Data. For the phase-II portion, fewer patients on nintedanib (87.1\%) vs. sorafenib $(96.8 \%)$ had investigatordefined drug-related $\mathrm{AEs}$ and fewer patients on nintedanib (67.7\%) experienced grade 3 or higher AEs compared with those on sorafenib (90.3\%). AEs occurring during the phase-II portion are summarised in supplementary Table S7. A total of 25 patients had AEs leading to dose reduction; 12 (19.4\%) in the nintedanib and 13 $(41.9 \%)$ in the sorafenib group (supplementary Table S8). AEs leading to drug discontinuation occurred in $28(45.2 \%)$ patients in the nintedanib group and $7(22.6 \%)$ patients in the sorafenib group (supplementary Table S8). None of the patients taking sorafenib had grade 4 or $5 \mathrm{AEs}$ that led to drug discontinuation, whereas for nintedanib four patients each had grade 4 AEs of hypertensive crisis, oesophageal varices haemorrhage, fatigue, asthenia and decreased performance status, plus one patient each with grade 5 general physical health deterioration and PD that led to drug discontinuation (none of which were drug related except for hypertensive crisis, fatigue and asthenia).

AEs associated with VEGF pathway inhibition, and other anygrade AEs of special interest, included (for nintedanib vs. sorafenib) specific liver-related investigations (24.2\% vs. $25.8 \%)$, bleeding ( $29.0 \%$ vs. $22.6 \%)$, rash $(21.0 \%$ vs. $38.7 \%)$, hypertension (14.5\% vs. $9.7 \%)$, cutaneous adverse reactions (4.8\% vs. $19.4 \%)$, thromboembolic events (1.6\% vs. $12.9 \%)$ and gastrointestinal $(\mathrm{Gl})$ perforation ( $0 \%$ vs. 3.2\%). No arterial thromboembolic events were reported. Supplementary Table S9 shows grade $\geq 3$ AEs of special interest occurring in all the dose cohorts for groups I and II.

Frequently occurring any-grade AEs are summarised in Table 2. Nausea (48.4\% vs. $29.0 \%)$, vomiting (38.7\% vs. $29.0 \%)$ and upper abdominal pain $(25.8 \%$ vs. $12.9 \%)$ occurred $>10 \%$ more frequently with nintedanib compared with sorafenib. Palmar-plantar 
erythrodysesthesia syndrome (35.5\% vs. $1.6 \%)$, alopecia (35.5\% vs. $4.8 \%)$ and rash $(22.6 \%$ vs. $9.7 \%)$ were more frequent with sorafenib compared with nintedanib (Table 2). Grade $\geq 3$ palmar-plantar erythrodysesthesia syndrome occurred in $22.6 \%$ of patients on sorafenib and no patients on nintedanib. AEs of $\geq$ grade 3 occurring in $\geq 5 \%$ of patients are summarised in Table 2 . There were 9 (14.5\%) patients on nintedanib and $3(9.7 \%)$ on sorafenib for whom AEs led to death; this was related to tumour progression for both drugs for all but one patient in the nintedanib group who died of interstitial lung disease, for which a causal relationship to the study drug could not be excluded.

\section{DISCUSSION}

This trial showed that nintedanib had antitumour activity and suggests it had similar efficacy with sorafenib, with a tolerable and different $A E$ profile, in mainly Caucasian patients with advanced HCC. The trial design complied with European Association for the Study of the Liver (EASL) recommendations for HCC trials ${ }^{16}$, as well as those for clinical oncology trials, ${ }^{17}$ using a randomised design with an active comparator, and was conducted to determine whether a high probability of success might be indicated for phase III trials, rather than to obtain definitive efficacy information. There were no pre-planned criteria for progression to a phase III trial, however. The trial used outcome measures recommended for use in phase-Il trials in $\mathrm{HCC}_{1}^{13}$ and as is common with parallel-group designs was open-label to better monitor safety on an ongoing basis and because of the different safety profiles and different rules for dose interruptions and reductions between the nintedanib and sorafenib groups. A comparable trial with nintedanib in Asian patients found similar results. ${ }^{14,15}$

In the phase-I portion, the area under the curve for nintedanib was broadly comparable to that found in other malignancies. ${ }^{18,19}$ Nintedanib is metabolised and mainly excreted via the liver ${ }^{12}$ such that liver impairment may influence nintedanib pharmacokinetics. Thus, an exploratory objective of this trial was to describe the effect of liver function assessed by AST/ALT plasma concentrations at study baseline (by allocation of patients to group I or II) and Child-Pugh classification on the PK parameters of nintedanib and its metabolites. Patients were stratified into two groups according to baseline liver function and the MTD was determined to be the same ( $200 \mathrm{mg}$ bid) for both groups with no significant differences in PK parameters. No DLTs occurred during the MTD determination period. The main DLTs occurring after the MTD determination period were reversible liver enzyme elevations. In the phase-Il portion of the trial, a higher proportion of patients in the sorafenib group had severe AEs, drug-related AEs and $A E s$ leading to dose reductions compared with patients in the nintedanib group, while a higher proportion of patients in the nintedanib group (45.2\%) had AEs leading to drug discontinuation compared with those in the sorafenib group (22.6\%). Nonetheless, despite this high rate of nintedanib discontinuation, the duration of nintedanib treatment was longer than that of sorafenib and the dose intensity of nintedanib was better, indicating that nintedanib is reasonably tolerated relative to sorafenib. Approximately a quarter of patients on nintedanib experienced GI AEs of grade 3 or higher. This rate was higher than that with sorafenib $(9.7 \%)$, underscoring the importance of close clinical monitoring for $\mathrm{Gl}$ events, especially given the large impact of Gl toxicities on quality of life. The higher rates of variceal bleeding with nintedanib, including that leading to drug discontinuation, suggest baseline endoscopy and control of varices could be a prudent strategy prior to starting nintedanib. Any-grade drugrelated $A E s$ for sorafenib were generally similar to those in the SHARP trial, ${ }^{7}$ although occurring at higher rates in the present trial, particularly for diarrhoea $(67.7 \%$ vs. $39 \%$ in SHARP) and palmar-plantar erythrodysesthesia syndrome $(35.5 \%$ vs. $21 \%$ in SHARP).
Allowing for small patient numbers and wide confidence intervals, the efficacy in terms of TTP and OS for sorafenib in this trial is broadly comparable to that reported in the SHARP trial, which was also conducted in a predominantly European population.

Limitations of this trial include the fact that correlations between TTP and PFS with OS still need to be established (a problem common to all trials in the setting of HCC). Because the trial was not blinded or powered to detect a significant difference in OS, further blinded, randomised studies would be required to interrogate potential survival benefits of nintedanib over sorafenib. The patients included in the phase-II portion were untreated, first-line patients. Given the limited benefit of sorafenib in this setting, documented progressive disease before inclusion could have been a better way to identify potential differences between sorafenib and nintedanib. Data on subsequent post-progression treatment were not mandated, such that its impact on OS could not be assessed. In contrast with sorafenib, nintedanib has activity inhibiting FGF receptor signalling. Although the FGF receptor status of patients was not assessed in this study, future studies could examine the FGF status of responders to nintedanib.

In conclusion, the current trial suggests nintedanib may have similar efficacy to sorafenib in patients with advanced HCC, with a tolerable and different safety profile, but with higher VEGF-related toxicity. The results suggest that nintedanib could be a suitable partner for combination studies in HCC.

\section{ACKNOWLEDGEMENTS}

We thank the patients and their families and the investigators who participated in this trial, as well as all the members of the study team. We also thank Rolf Kaiser and Arne Wenz for their contributions during trial preparation and conduct, in addition to their thorough reviews of the manuscript. Medical writing services and editorial support, supported financially by Boehringer Ingelheim, were provided by Steven Tresker of Cactus Communications during the preparation of this report. Funding: this work was supported by Boehringer Ingelheim. This work was supported by the NIHR Liverpool Biomedical Research Unit [to D.H.P], the Liverpool Experimental Cancer Medicine Centre [to D.H.P.], the NIHR/Wellcome UCLH Clinical Research Facility [to T.M.], the NIHR UCL Hospitals Biomedical Research Centre [to T.M.] and the UCL Experimental Cancer Medicine Centre [to T.M.].

\section{ADDITIONAL INFORMATION}

Supplementary information is available for this paper at https://doi.org/10.1038/ s41416-018-0051-8.

Competing interests: D.H.P reports travel expenses from Boehringer Ingelheim and grants from Bayer, outside the submitted work. A-B.L., J.H., M.S., and D.S. are employees of Boehringer Ingelheim. Y.T.M reports personal fees from Bayer during the conduct of the study. T.M. reports consulting and conference travel expenses. M. $\mathrm{P}-\mathrm{R}$ reports per patient fees for a phase III trial from Boehringer Ingelheim during the conduct of the study; and grants and personal fees from Bayer Healthcare, Lilly, Arqle-Daiichi, and other from ONXEO, outside the submitted work. P.R., J.G., L.F. and A.D report no relevant conflicts of interest.

\section{REFERENCES}

1. Semela, D. \& Dufour, J. F. Angiogenesis and hepatocellular carcinoma. J. Hepatol. 41, 864-880 (2004)

2. Whittaker, S., Marais, R. \& Zhu, A. X. The role of signaling pathways in the development and treatment of hepatocellular carcinoma. Oncogene 29, 4989-5005 (2010).

3. Zhu, A. X., Duda, D. G., Sahani, D. V. \& Jain, R. K. HCC and angiogenesis: possible targets and future directions. Nat. Rev. Clin. Oncol. 8, 292-301 (2011).

4. Chan, S. L. \& Yeo, W. Targeted therapy of hepatocellular carcinoma: present and future. J. Gastroenterol. Hepatol. 27, 862-872 (2012).

5. Sandhu, D. S., Baichoo, E. \& Roberts, L. R. Fibroblast growth factor signaling in liver carcinogenesis. Hepatology 59, 1166-1173 (2014).

6. Cheng, A. L. et al. Efficacy and safety of sorafenib in patients in the Asia-Pacific region with advanced hepatocellular carcinoma: a phase III randomised, doubleblind, placebo-controlled trial. Lancet Oncol. 10, 25-34 (2009). 
7. Llovet, J. M. et al. Sorafenib in advanced hepatocellular carcinoma. N. Engl. J. Med. 359, 378-390 (2008)

8. Abou-Alfa, G. K. \& Venook, A. P. The antiangiogenic ceiling in hepatocellular carcinoma: does it exist and has it been reached? Lancet Oncol. 14, e283-e288 (2013).

9. Worns, M. A. \& Galle, P. R. HCC therapies-lessons learned. Nat. Rev. Gastroenterol. Hepatol. 11, 447-452 (2014).

10. Hilberg, F. et al. BIBF 1120: triple angiokinase inhibitor with sustained receptor blockade and good antitumor efficacy. Cancer Res. 68, 4774-4782 (2008).

11. Kudo, K. et al. Antitumor activity of BIBF 1120 , a triple angiokinase inhibitor, and use of VEGFR2+pTyr+peripheral blood leukocytes as a pharmacodynamic biomarker in vivo. Clin. Cancer Res. 17, 1373-1381 (2011).

12. Stopfer, P. et al. Pharmacokinetics and metabolism of BIBF 1120 after oral dosing to healthy male volunteers. Xenobiotica 41, 297-311 (2011).

13. Llovet, J. M. et al. Design and endpoints of clinical trials in hepatocellular carcinoma. J. Natl Cancer Inst. 100, 698-711 (2008).

14. Yen C.-J., et al. Early data from a phase I study of nintedanib (BIBF 1120) in Asian patients with advanced hepatocellular carcinoma. Ann. Oncol. 23, abstr. 744P (2012).

15. Cheng, A.-L et al. Efficacy And Safety of Nintedanib Versus Sorafenib in Asian Patients with Advanced Hepatocellular Carcinoma: A Randomized Phase II Trial. (American Society of Clinical Oncology Gastrointestinal Cancers Symposium, San Francisco, 2015)

16. European Association for the Study of the Liver, European Organisation for Research and Treatment of Cancer. EASL-EORTC clinical practice guidelines: management of hepatocellular carcinoma. J. Hepatol. 56, 908-943 (2012).
17. Cannistra, S. A. Phase II trials in journal of clinical oncology. J. Clin. Oncol. 27, 3073-3076 (2009).

18. Mross, K. et al. Phase I study of the angiogenesis inhibitor BIBF 1120 in patients with advanced solid tumors. Clin. Cancer Res. 16, 311-319 (2010).

19. Okamoto, I. et al. Phase I safety, pharmacokinetic, and biomarker study of BIBF 1120 , an oral triple tyrosine kinase inhibitor in patients with advanced solid tumors. Mol. Cancer Ther. 9, 2825-2833 (2010).

cc) (1)

Open Access This article is licensed under a Creative Commons Attribution 4.0 International License, which permits use, sharing, adaptation, distribution and reproduction in any medium or format, as long as you give appropriate credit to the original author(s) and the source, provide a link to the Creative Commons license, and indicate if changes were made. The images or other third party material in this article are included in the article's Creative Commons license, unless indicated otherwise in a credit line to the material. If material is not included in the article's Creative Commons license and your intended use is not permitted by statutory regulation or exceeds the permitted use, you will need to obtain permission directly from the copyright holder. To view a copy of this license, visit http://creativecommons. org/licenses/by/4.0/

c C) The Author(s) 2018 